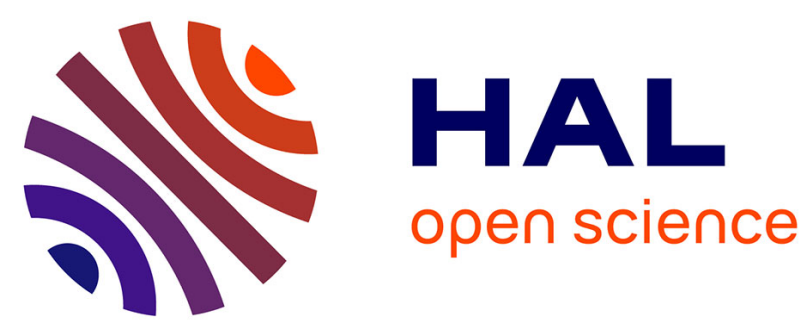

\title{
Structure-determined thermoelectric properties of Bi2Se3 thin films deposited by vapour-solid technique
}

\author{
J. Andzane, K. Buks, M. Zubkins, Mikhael Bechelany, M. Marnauza, M.
} Baitimirova, D. Erts

\section{- To cite this version:}

J. Andzane, K. Buks, M. Zubkins, Mikhael Bechelany, M. Marnauza, et al.. Structure-determined thermoelectric properties of Bi2Se3 thin films deposited by vapour-solid technique. 2018 IEEE 18th International Conference on Nanotechnology (IEEE-NANO), Jul 2018, Cork, Ireland. pp.1-5, 10.1109/NANO.2018.8626225 . hal-03247607

\section{HAL Id: hal-03247607 \\ https://hal.science/hal-03247607}

Submitted on 3 Jun 2021

HAL is a multi-disciplinary open access archive for the deposit and dissemination of scientific research documents, whether they are published or not. The documents may come from teaching and research institutions in France or abroad, or from public or private research centers.
L'archive ouverte pluridisciplinaire HAL, est destinée au dépôt et à la diffusion de documents scientifiques de niveau recherche, publiés ou non, émanant des établissements d'enseignement et de recherche français ou étrangers, des laboratoires publics ou privés. 


\title{
Structure-determined thermoelectric properties of $\mathrm{Bi}_{2} \mathrm{Se}_{3}$ thin films deposited by vapour-solid technique.
}

\author{
J. Andzane ${ }^{1}$, K. Buks ${ }^{1}$, M. Zubkins ${ }^{2}$, M. Bechelany ${ }^{3}$, M. Marnauza ${ }^{1}$, M. Baitimirova ${ }^{1}$, and D. Erts ${ }^{1}$ \\ ${ }^{1}$ Institute of Chemical Physics, University of Latvia, Riga, Latvia, email: jana.andzane@lu.lv \\ ${ }^{2}$ Institute of Solid State Physics, University of Latvia, Riga, Latvia \\ ${ }^{3}$ European Institute of Membranes, University of Montpellier, CNRS, ENSCM, Montpellier, France
}

\begin{abstract}
In this work, a simple catalyst-free vapour-solid deposition method is applied for controlled obtaining of two types (planar and disordered) continuous $\mathrm{Bi}_{2} \mathrm{Se}_{3}$ nanostructured thin films on different (fused quartz/glass, mica, graphene) substrates. Performed for the deposited thin films transport and thermoelectric characterization (type, concentration and mobility of the main charge carriers, Seebeck coefficient and power factor) showed that proposed deposition method allows to fabricate "low-doped" $\mathrm{Bi}_{2} \mathrm{Se}_{3}$ thin films with power factor comparable and even higher than reported for the $\mathrm{Bi}_{2} \mathrm{Se}_{3}$ thin films fabricated by molecular beam epitaxy technique.
\end{abstract}

\section{INTRODUCTION}

Bismuth selenide $\left(\mathrm{Bi}_{2} \mathrm{Se}_{3}\right)$ is known as a narrow band gap semiconductor with excellent thermoelectric (TE) properties for near-room temperatures. $\mathrm{Bi}_{2} \mathrm{Se}_{3}$ has a rhombohedral crystal structure in the space group $D_{3 d}^{5}(R \overline{3} \mathrm{~m})$ and consists of charge neutralized layers bonded together with weak Van der Waals forces along the c-axis. Each charge neutralized layer (quintuple layer, Q-layer) is formed by five covalently bonded atomic sheets (Se-Bi-Se-Bi-Se).

The main strategies for increase of the TE efficiency of materials include the use of numerous interfaces for efficient phonon scattering resulting in reduction of the lattice thermal conductivity, and the use of quantum confinement phenomena to increase the Seebeck coefficient of the material. For the best near-room temperature TE materials as bismuth chalcogenides, which are found to be topological insulators, quantum confinement introduced by the downsizing down to nanoscale was proposed an efficient method for simultaneous suppression of the thermal conductivity and enhancing of thermoelectrical power factor [1].

For the practical applications, the preferred method for bismuth chalcogenide thin films preparation is simple costeffective catalyst-free vapour-solid deposition method using different substrates like Si, glass, mica [2], indium tin oxide covered glass [3] and graphene [4].

In this work, the catalyst-free vapour-solid deposition technique [5] is applied for controlled obtaining of two types of continuous nanostructured $\mathrm{Bi}_{2} \mathrm{Se}_{3}$ thin films on different substrates like fused quartz/glass, mica and chemical vapour deposition (CVD) graphene. Planar thin films, consisting of coalesced nanoplates planar to the substrate surface, are suitable for both in-plane and through-plane measurements and layered devices. In turn, disordered thin films, consisting of both planar and oriented under random angles relative to the substrate surface nanoplates, have been reported useful for sandwich- type devices [4], as well as are more suitable for sensor applications due to high surface-to-volume ratio. Structure, electron transport and thermoelectric properties of these thin films are determined and discussed.

\section{EXPERIMENTAL}

\section{A. Deposition of the thin films.}

$\mathrm{Bi}_{2} \mathrm{Se}_{3}$ nanostructured thin films were deposited by previously reported catalyst-free vapour-solid deposition method using quartz tube furnace (GCL-1100X, MTI Corp) [4]. Source material evaporation temperature was $585^{\circ} \mathrm{C}$. Synthesis of thin films occurred without carrier gas flow except for obtaining of disordered $\mathrm{Bi}_{2} \mathrm{Se}_{3}$ thin films on graphene surface, when the temporary gas flow (dynamic pressure 50-150 Torr) was introduced into the furnace tube during the cooling process for the temperature interval $535-$ $475^{\circ} \mathrm{C}$. Typical thicknesses of the deposited thin films are 100$200 \mathrm{~nm}$ and depend on the deposition time and amount of the source material.

\section{B. Substrate preparation}

Quartz/glass substrates were washed in 2-propanol and distilled water, and dried under $\mathrm{N}_{2}$ flow. Muscovite mica sheets (Agar Scientific) were mechanically cleaved immediately before the deposition process. Monolayer graphene was prepared by chemical vapour deposition (CVD) method on a copper foil and transferred on the quartz/glass substrates using polymer-assisted technique described elsewhere [4].

\section{Investigation methods}

Morphology, thickness, structure and composition of obtained $\mathrm{Bi}_{2} \mathrm{Se}_{3}$ nanoplates and nanostructured thin films were inspected using field emission scanning electron microscope (SEM) Hitachi S-4800 equipped with an energy-dispersive Xray (EDX) analyser Bruker XFLASH 5010 and atomic force microscope (AFM) Asylum Research MFP-3D.

Transport properties of the thin films were measured using Hall effect measurement system HMS-5000. Thermoelectric measurements were carried out for the temperature range 295 - $320 \mathrm{~K}$ by home-made device calibrated with Standard Reference Material 3451 for low temperature Seebeck coefficient (NIST).

\section{RESUlTS AND DISCUSSION}

As morphology of the nanostructured thin films deposited by catalyst-free vapour-solid technique is governed by the properties of the substrate surface, to obtain films $\mathrm{Bi}_{2} \mathrm{Se}_{3}$ thin films of a certain structure deposition was made on three 
different types of substrates: monolayer CVD graphene, mica and fused quartz or glass. At the beginning of the deposition process, the natural diffusion of the evaporated source material from the hot centre of the furnace tube results in random nucleation and further growth of $\mathrm{Bi}_{2} \mathrm{Se}_{3}$ nanoplates directly on the substrate surface, which corresponds to Vollmer-Weber (island) growth mode. Due to the intrinsically anisotropic bonding nature, the most energetically favourable orientation of $\mathrm{Bi}_{2} \mathrm{Se}_{3}$ nuclei is Q-layers parallel to the substrate surface. The further lateral growth of the $\mathrm{Bi}_{2} \mathrm{Se}_{3}$ nuclei occurs symmetrically and faster than vertical due to the diffusion of adatoms to the edges of the nanoplates over its Se-passivated top surface [6]. The symmetry of the nanoplates may be affected by the anisotropy of the substrate surface (Fig. $1 \mathrm{a}-\mathrm{c}$ ), rising from the presence of grain boundaries or dangling chemical bonds on the substrate surface. Here, this was used for obtaining of thin films consisting of nanoplates of a certain orientation.

\section{B. Planar thin films}

Planar thin films can be obtained on the substrates not having dangling bonds on their surface (mica, graphene) under the following synthesis parameters: process pressure $\sim 2-3$ Torr, substrate temperature $330-380^{\circ} \mathrm{C}$, no carrier gas flow. The nanoplates formed during the start phase of the deposition coalesce together forming continuous planar thin film (Fig. 1 a,b,d,e,f). Such thin films cannot be obtained on not-passivated fused quartz or glass substrates due to the influence of chemical surface defects originating from their structure [7]. The thin films that can be formed on the quartz/glass surfaces are discussed in the next section.

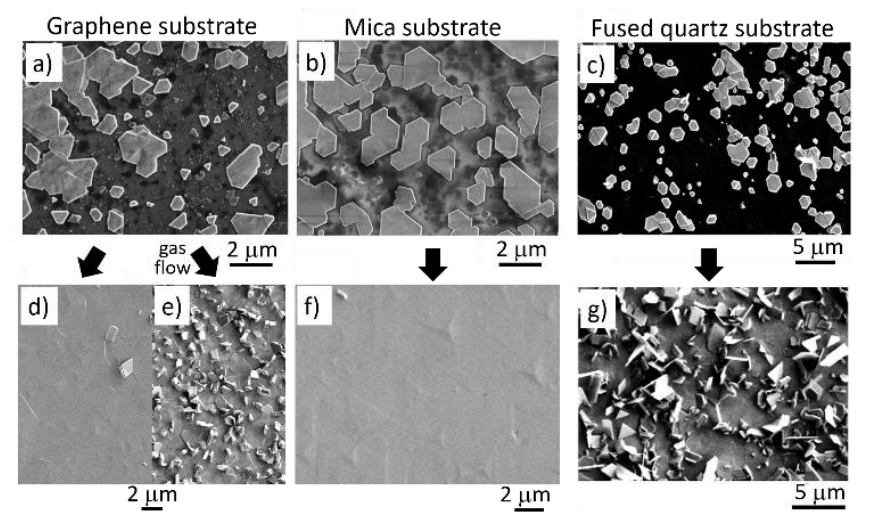

Fig. 1 a-b) SEM images of heteroepitaxial partially merged $\mathrm{Bi}_{2} \mathrm{Se}_{3}$ nanoplates on graphene (a) and mica (b) surfaces; c) SEM image of $\mathrm{Bi}_{2} \mathrm{Se}_{3}$ nuclei on glass surface; $d$-f) SEM images of planar ( $\mathrm{d}$ - on graphene, $\mathrm{f}-$ on mica) and mixed (e - on graphene, $\mathrm{g}$ - on glass) continuous nanostructured $\mathrm{Bi}_{2} \mathrm{Se}_{3}$ thin films.

\section{Disordered thin films.}

Disordered $\mathrm{Bi}_{2} \mathrm{Se}_{3}$ thin films can be easily obtained on the fused quartz of glass substrates under the same parameters as for planar thin films. The dangling bonds originating from the defects on quartz/glass surface are introducing defects in the crystalline structure of growing nanoplates and promoting formation of other phases of $\mathrm{Bi}_{2} \mathrm{Se}_{3}$ crystals, resulting in formation of $\mathrm{Bi}_{2} \mathrm{Se}_{3}$ thin films consisting of disordered nanoplates (Fig. $1 \mathrm{c}, \mathrm{g}$ ).

Obtaining of disordered thin films on substrates like graphene or mica, promoting heteroepitaxial growth of $\mathrm{Bi}_{2} \mathrm{Se}_{3}$ nanostructures, is a challenge. However, for the CVD graphene with grainy structure this can be achieved by the introduction of the temporary carrier gas flow with dynamic pressure starting from 50 Torr into the process tube during the $\mathrm{Bi}_{2} \mathrm{Se}_{3}$ deposition (as described in the Experimental section). Presumably, the carrier gas flow causes rapid increase of vaporized source material concentration in the deposition area, thus promoting formation of vertical nanoplates at the facing grain boundaries edges of heteroepitaxial nanoplates. This is followed by formation of continuous nanostructured $\mathrm{Bi}_{2} \mathrm{Se}_{3}$ thin film consisting of mix of planar as well as oriented under different angles relative to the substrate surface nanoplates (Fig. 1 e) [4]. It should be noted that the temporary gas flow with dynamic pressure up to 150 Torr does not promote formation of randomly oriented nanoplates on mica surface. This fact indirectly confirms that in the case of CVD graphene substrate the formation of randomly oriented nanoplates is promoted by the grain boundaries.

\section{Structural and electron transport properties of $\mathrm{Bi}_{2} \mathrm{Se}_{3}$ thin films.}

The percentage of $\mathrm{Bi}$ and $\mathrm{Se}$ found in the thin films corresponds to stoichiometric $\mathrm{Bi}_{2} \mathrm{Se}_{3}(40 \% \mathrm{Bi}$ : $60 \% \mathrm{Se})$. Diffraction peaks of XRD patterns obtained for the planar and disordered $\mathrm{Bi}_{2} \mathrm{Se}_{3}$ thin films (Fig. 2 a) can be indexed to the rhombohedral structure with cell units of $\mathrm{a}=\mathrm{b}=4.139 \AA$ and $c=28.636 \AA$ ([8], ref. code 00-033-0124). The observed at the XRD diffraction patterns of $\mathrm{Bi}_{2} \mathrm{Se}_{3}$ thin films $\left(\begin{array}{lll}0 & 0 & 1\end{array}\right)$ peaks are significantly stronger than those for the standard powder diffraction pattern, while characteristic for bulk $\mathrm{Bi}_{2} \mathrm{Se}_{3}$ (1010) and (110) diffraction peaks are lacking, but intensity of (015) peak is very low (Fig. 2 b). With an exception of (015) peak, the affiliation of all presented in the XRD patterns diffraction peaks to a group ( $\left.\begin{array}{llll}0 & 0 & 3 n\end{array}\right)$ indicates nearly pure growth of the thin films in single-crystalline phase with c-axis oriented perpendicularly to the substrate.

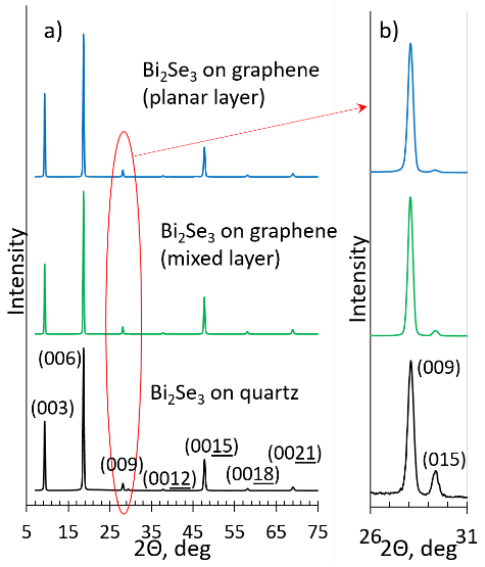

Fig. 2 Comparison between XRD patterns of continuous nanostructured $\mathrm{Bi}_{2} \mathrm{Se}_{3}$ thin films deposited on quartz and graphene substrates.

Closer look at XRD patterns (Fig. 2 b) shows that the intensity of (015) diffraction peak for planar $\mathrm{Bi}_{2} \mathrm{Se}_{3}$ thin film deposited is negligible, while slightly raises for the disordered thin film deposited on graphene substrates, and becomes noticeable for the disordered $\mathrm{Bi}_{2} \mathrm{Se}_{3}$ thin film deposited on 
quartz substrate. This corresponds to the SEM images of the disordered thin films (Fig. $1 \mathrm{e}, \mathrm{g}$ ), showing higher proportion of oriented under different angles relative to the substrate surface nanoplates per unit area for the thin film deposited on quartz. At the same time, the intensity of (015) peak for the disordered $\mathrm{Bi}_{2} \mathrm{Se}_{3}$ thin film deposited on quartz is still very low in comparison with other peaks, which may indicate that the disordered nanoplates are formed only on the top layer of the planar thin film.

Electrical transport data for all characterized samples are summarized in Table 1.

Table 1. Electrical transport and thermoelectric properties of continuous nanostructured $\mathrm{Bi}_{2} \mathrm{Se}_{3}$ thin films deposited on different substrates.

\begin{tabular}{|c|c|c|c|c|c|c|}
\hline No. & Substrate & $\begin{array}{c}\text { Charge carrier } \\
\text { concentration, } \\
\mathrm{cm}^{-3}\end{array}$ & $\begin{array}{c}\text { Charge } \\
\text { carrier } \\
\text { mobility, } \\
\mathrm{cm}^{2} /(\mathrm{V} \cdot \mathrm{s})\end{array}$ & $\begin{array}{l}\text { Conductivity } \\
\mathrm{S} / \mathrm{cm}\end{array}$ & $\begin{array}{c}\text { Absolute } \\
\text { value of } \\
\text { Seebeck } \\
\text { coefficient } \\
\mu \mathrm{V} / \mathrm{K}\end{array}$ & $\begin{array}{c}\text { Power } \\
\text { factor, } \\
\mu \mathrm{W} /\left(\mathrm{cm} \cdot \mathrm{K}^{2}\right)\end{array}$ \\
\hline 1 & \multirow{4}{*}{ Quartz/glass } & $-2.2 \cdot 10^{18}$ & 510 & 182 & 182 & 6 \\
\hline 2 & & $-3.3 \cdot 10^{18}$ & 427 & 231 & 122 & 3.45 \\
\hline 3 & & $-4.7 \cdot 10^{18}$ & 356 & 271 & 74 & 1.45 \\
\hline 4 & & $-1.95 \cdot 10^{18}$ & 279 & 86.5 & 143 & 1.75 \\
\hline 5 & \multirow{3}{*}{ Mica } & $-3.9 \cdot 10^{18}$ & 339 & 211 & 209 & 9.2 \\
\hline 6 & & $-2.35 \cdot 10^{18}$ & 453 & 171 & 162 & 4.5 \\
\hline 7 & & $-2.9 \cdot 10^{18}$ & 441 & 207 & 227 & 10.7 \\
\hline 8 & \multirow{5}{*}{ Graphene } & $3.6 \cdot 10^{19}$ & 500 & 287 & 33 & 0.3 \\
\hline 9 & & $4.2 \cdot 10^{18}$ & 257 & 172 & 89 & 1.35 \\
\hline 10 & & $2 \cdot 10^{19}$ & 110 & 352 & 48 & 0.8 \\
\hline 11 & & $1.3 \cdot 10^{19}$ & 148 & 556 & 36 & 0.73 \\
\hline 12 & & $1.25 \cdot 10^{19}$ & 360 & 723 & 18 & 0.23 \\
\hline
\end{tabular}

Planar and disordered thin films deposited on quartz/glass and mica substrates were found to be n-type due to native defects such as $\mathrm{Se}_{\mathrm{Bi}}$ antisites and/or Se vacancies, acting as active n-type dopants [9]. Charge carrier concentrations in these thin films were in the range from $\sim 2 \cdot 10^{18}$ up to $4.7 \cdot 10^{18} \mathrm{~cm}^{-3}$ with mobilities varying between 120 and 510 $\mathrm{cm}^{2} /(\mathrm{V} \cdot \mathrm{s})$.

Presumably, such scatter of the experimental results origins from the different concentration of defects in the thin films. The highest mobility values showed by planar $(\sim 450$ $\left.\mathrm{cm}^{2} /(\mathrm{V} \cdot \mathrm{s})\right)$ and disordered $\left(425-510 \mathrm{~cm}^{2} /(\mathrm{V} \cdot \mathrm{s})\right)$ thin films are close to the values $\left(320-1000 \mathrm{~cm}^{2} /(\mathrm{V} \cdot \mathrm{s})\right)$ reported for the "lowdoped" $\mathrm{Bi}_{2} \mathrm{Se}_{3}$ nanostructures with the level of native charged impurity disorder in the thin film in order of $10^{13} \mathrm{~cm}^{-2}[10]$.

The different from "low-doped" $\mathrm{Bi}_{2} \mathrm{Se}_{3}$ nanostructures values of charge carrier mobilities and concentrations may be related to the higher concentration of charge impurities and defects in the thin film. For instance, lower charge carrier mobility and at the same time higher charge carrier concentration (Table 1, samples 3 and 5), may be related to positively charged defects in the grain boundaries $\left(\mathrm{Se}_{\mathrm{Bi}}\right.$ antisites/Se vacancies), known to increase charge carrier concentration by producing of excess electrons. In turn, the lower carrier concentrations and at the same time lower mobility (Table 1, samples 1 and 4) may be addressed to increased concentration of defects (charge impurities on the grain boundaries, vacancies) in the thin film, as well as to discontinuities in the thin films formed during the deposition.

The temperature dependence of charge carrier mobilities for disordered and planar $\mathrm{Bi}_{2} \mathrm{Se}_{3}$ thin films (Table 1, samples 2 and 6) are shown in log-log scale in Fig. 3 a. It has a power law scaling $\left(\sim \mathrm{T}^{\mathrm{n}}\right)$ with exponents $\mathrm{n} \approx-0.42$ and -0.45 for the disordered and planar thin films respectively. These exponents suggest that for the temperatures $\geq 100 \mathrm{~K}$ two scattering processes in these thin films may occur: electron-phonon $\left(\sim \mathrm{T}^{-3 / 2}\right)$ scattering and scattering on interfacial charged defects $\left(\sim \mathrm{T}^{3 / 2}\right)$, which may act as selective filter of low-energy minority charge carriers, thus improving the TE efficiency of the thin films [11].
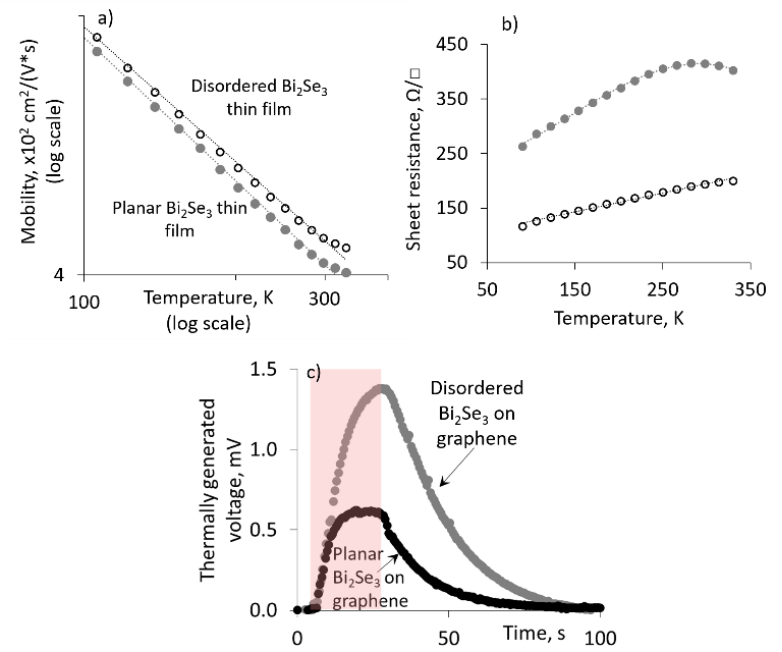

Fig. 3 a) Temperature dependence of the charge carrier mobility and b) temperature dependence of sheet resistance of planar (grey circles) and disordered (hollow circles) $\mathrm{Bi}_{2} \mathrm{Se}_{3}$ thin films; c) thermally generated $(\Delta \mathrm{T}=16 \mathrm{~K}$ ) in through-plane measurement configuration voltage of planar (black circles) and disordered (grey circles) $\mathrm{Bi}_{2} \mathrm{Se}_{3}$ thin films deposited on graphene substrates. The temperature difference of $16 \mathrm{~K}$ was applied between the top and bottom graphene electrodes for $20 \mathrm{~s}$ (illustrated by the pink rectangular).

The temperature dependence of the sheet resistance showed metallic behaviour for disordered $\mathrm{Bi}_{2} \mathrm{Se}_{3}$ thin film, while the planar $\mathrm{Bi}_{2} \mathrm{Se}_{3}$ thin film demonstrated a hump with a maximum around $280 \mathrm{~K}$ (Fig. 3b), which may indicate multiband transport typical for low-doped topological insulator nanostructures [5].

All $\mathrm{Bi}_{2} \mathrm{Se}_{3}$ thin films deposited on graphene substrates showed p-type conductivity (Table 1) and higher in comparison with deposited on mica and quartz/glass substrates $\mathrm{Bi}_{2} \mathrm{Se}_{3}$ thin films charge carrier concentrations $\left(4.2 \cdot 10^{18}-3.6 \cdot 10^{19} \mathrm{~cm}^{-3}\right)$. However, the charge carrier mobilities of these samples varied between 110 and $500 \mathrm{~cm}^{2} /(\mathrm{V} \cdot \mathrm{s})$ (Table 1, samples 8-12), which is comparable with the charge carrier mobilities of $\mathrm{Bi}_{2} \mathrm{Se}_{3}$ thin films obtained on quartz/glass and mica substrates. Possibly, the p-type conductivity and higher charge carrier concentrations mirror the properties of the graphene substrates, accompanied by some impact from the $\mathrm{Bi}_{2} \mathrm{Se}_{3}$ thin film, as the electrical contacts were made to the $\mathrm{Bi}_{2} \mathrm{Se}_{3}$ thin films, while dominating charge carrier transport occurs through the graphene substrate due to its very low electrical resistance.

\section{E. Thermoelectric properties of continuous $\mathrm{Bi}_{2} \mathrm{Se}_{3}$ thin films.}

Seebeck coefficient values and estimated power factors of the $\mathrm{Bi}_{2} \mathrm{Se}_{3}$ thin films are listed in Table 1 .

The average absolute values of a Seebeck coefficient at room temperature for $\mathrm{Bi}_{2} \mathrm{Se}_{3}$ thin films (except ones deposited on graphene and discussed later in text) were respectively 130 $\mu \mathrm{V} / \mathrm{K}$ for the disordered thin films deposited on quartz/glass 
substrates (Table 1, samples 1-4) and $200 \mu \mathrm{V} / \mathrm{K}$ for the planar thin films (Table 1, samples 5-7). These values exceed the absolute values of Seebeck coefficient reported for $\mathrm{Bi}_{2} \mathrm{Se}_{3}$ nanostructures synthesized via solvothermal method (115 $\mu \mathrm{V} / \mathrm{K}$ ) [12] and $\mathrm{Bi}_{2} \mathrm{Se}_{3}$ thin films with thickness 30 quintuple thin films grown by molecular beam epitaxy $(104.3 \mu \mathrm{V} / \mathrm{K})$ [13], and are 2-3 times higher than the absolute value of the Seebeck coefficient of the bulk $\mathrm{Bi}_{2} \mathrm{Se}_{3}$ at room temperature (59 $\mu \mathrm{V} / \mathrm{K}$ ) [14]. Probably, the high values of Seebeck coefficient can be explained by selective low energy charge carriers filtering on the interfacial charged defects between the nanoplates composing the $\mathrm{Bi}_{2} \mathrm{Se}_{3}$ thin films, similarly to the effect reported for n-type $\mathrm{Bi}_{2} \mathrm{Te}_{3}$ few-layered flakes [11].

The power factors calculated for the "low-doped" disordered $\mathrm{Bi}_{2} \mathrm{Se}_{3}$ thin films obtained on quartz/glass were 3.45-6 $\mu \mathrm{W} / \mathrm{cm} \cdot \mathrm{K}^{2}$, while planar $\mathrm{Bi}_{2} \mathrm{Se}_{3}$ thin films obtained on mica showed values up to $10.7 \mu \mathrm{W} / \mathrm{cm} \cdot \mathrm{K}^{2}$ at room temperature, which is close and even higher than the power factors reported for the MBE grown $\mathrm{Bi}_{2} \mathrm{Se}_{3}$ thin films (up to 6 $\mu \mathrm{W} / \mathrm{cm} \cdot \mathrm{K}^{2}$ ) and pulsed laser deposition (up to 5.54 $\mu \mathrm{W} / \mathrm{cm} \cdot \mathrm{K}^{2}$ ) methods [15]. Power factors of the disordered $\mathrm{Bi}_{2} \mathrm{Se}_{3}$ thin films with higher amount of defects (1.45-1.75 $\mu \mathrm{W} / \mathrm{cm} \cdot \mathrm{K}^{2}$, Table 1 , samples 3,4$)$ are comparable with the power factors reported for $\mathrm{Bi}_{2} \mathrm{Se}_{3}$ thin films grown by chemical solution $\left(1-1.5 \mu \mathrm{W} / \mathrm{cm} \cdot \mathrm{K}^{2}\right)$ [16].

The $\mathrm{Bi}_{2} \mathrm{Se}_{3}$ thin films deposited on graphene showed Seebeck coefficients spread in the range 18-89 $\mu \mathrm{V} / \mathrm{K}$ (avg. 45 $\mu \mathrm{V} / \mathrm{K})$. Considering that Seebeck coefficient of monolayer CVD graphene is reported to be $\sim 30 \mu \mathrm{V} / \mathrm{K}$ [17], it can be concluded that the result of in-plane measurements of the Seebeck coefficient $\mathrm{Bi}_{2} \mathrm{Se}_{3}$ layer on the graphene surface is most likely the combination of thermoelectric properties of graphene and thermoelectric effect given by the $\mathrm{Bi}_{2} \mathrm{Se}_{3}$ electrodes. Power factor of the $\mathrm{Bi}_{2} \mathrm{Se}_{3}$ thin films deposited on graphene were spread in the range $\left(0.23-1.35 \mu \mathrm{W} / \mathrm{cm} \cdot \mathrm{K}^{2}\right)$.

It should be noted that the thermoelectric properties of the $\mathrm{Bi}_{2} \mathrm{Se}_{3}$ thin films obtained on graphene were expected to be similar to the properties of $\mathrm{Bi}_{2} \mathrm{Se}_{3}$ thin films deposited on mica. While the thermoelectric properties of $\mathrm{Bi}_{2} \mathrm{Se}_{3}$ thin films deposited on graphene substrates may not be accurately measured in-plane, using graphene as a substrate for $\mathrm{Bi}_{2} \mathrm{Se}_{3}$ deposition and simultaneously as a top or bottom electrode is a good solution for through-plane thermoelectric characterization of $\mathrm{Bi}_{2} \mathrm{Se}_{3}$ nanostructured thin films. An example of through-plane measurements of the 200-nm thick planar and mixed $\mathrm{Bi}_{2} \mathrm{Se}_{3}$ thin films deposited on the graphene substrate and using another graphene layer as top electrode is shown in Fig. 3 c. In this experiment, the temperature gradient of $16 \mathrm{~K}$ was applied between the top- and bottom graphene electrodes for $20 \mathrm{~s}$ (illustrated in Fig. $3 \mathrm{c}$ as pink rectangle).

The voltage-time curves (Fig. 3 c) illustrate thermally generated by the samples voltage. The curves show rapid increase of thermally generated voltage when the temperature difference is applied to the electrodes, followed by saturation and decrease with the decrease of the temperature gradient between the graphene electrodes. As it is seen from the Fig. 3 c, the enclosed between two graphene sheets $\mathrm{Bi}_{2} \mathrm{Se}_{3}$ thin films showed pronounced response to the temperature difference of $16 \mathrm{~K}$ applied between the top and bottom electrodes. The nonplanar thin film showed nearly twice higher thermoelectric response in comparison with planar thin film, which agrees with previous works on similar structures [4].

\section{ACKNOWLEDGMENT}

This work was supported by the ERDF projects No 1.1.1.1/16/A/257 and 1.1.1.2/1/16/037.

\section{REFERENCES}

[1] M.S. Dresselhaus, G. Chen, M.Y. Tang, R.G. Yang, H. Lee, D.Z. Wang, Z. F. Ren, J.P. Fleurial, P. Gogna, New Directions for Low-Dimensional Thermoelectric Materials, Adv. Mater. 19, 1043, 2007

[2] J. T. Mlack, A. Rahman, G. L. Johns, K. J. T. Livi, N. Marković, Substrateindependent catalyst-free synthesis of high-purity $\mathrm{Bi}_{2} \mathrm{Se}_{3}$ nanostructures, Appl. Phys. Lett. 102, 193108, 2013

[3] J. Kosmaca, J. Andzane, M. Baitimirova, F. Lombardi, D. Erts, Role of Nanoelectromechanical Switching in the Operation of Nanostructured $\mathrm{Bi}_{2} \mathrm{Se}_{3}$ Interlayers between Conductive Electrodes, ACS Appl Mater Interfaces 8, 12257, 2016

[4] M. Baitimirova, J. Andzane, G. Petersons, R. Meija, R. Poplausks, M Romanova, D. Erts, Vapour-solid synthesis and enhanced thermoelectric properties of non-planar bismuth selenide nanoplates on graphene substrate, J. Mater. Sci. 51, 8224, 20163

[5] J. Andzane, G. Kunakova, S. Charpentier, V. Hrkac, L. Kienle, M. Baitimirova, T. Bauch, F. Lombardi, D. Erts, Catalyst-free vapour-solid technique for deposition of $\mathrm{Bi}_{2} \mathrm{Te}_{3}$ and $\mathrm{Bi}_{2} \mathrm{Se}_{3}$ nanowires/nanobelts with topological insulator properties, Nanoscale 7, 15935, 2015

[6] A. Zhuang, Y. Zhao, X. Liu, M. Xu, Y. Wang, U. Jeong, X. Wang, J. Zeng, Controlling the lateral and vertical dimensions of $\mathrm{Bi}_{2} \mathrm{Se}_{3}$ nanoplates via seeded growth, Nano Res. 8, 246, 2015

[7] S.-K. Jerng, K. Joo, Y. Kim, S.-M. Yoon, J. H. Lee, M. Kim, J. S. Kim, E. Yoon, S.-H. Chun, Y. S. Kim, Ordered growth of topological insulator $\mathrm{Bi}_{2} \mathrm{Se}_{3}$ thin films on dielectric amorphous $\mathrm{SiO}_{2}$ by MBE, Nanoscale 5 , 10618, 2013

[8] Natl. Bur. Stand. (U.S.) Monogr. 25, 18, 16, 1981

[9] L. Xue, P. Zhou, C. X. Zhang, C. Y. He, G. L. Hao, L. Z. Sun, J. X. Zhong, First-principles study of native point defects in $\mathrm{Bi}_{2} \mathrm{Se}_{3}$, AIP Advances 3 , 052105, 2013

[10] D. Kim, S. Cho, N. P. Butch, P. Syers, K. Kirshenbaum, S. Adam, J. Paglione, M. S. Fuhrer, Surface conduction of topological Dirac electrons in bulk insulating $\mathrm{Bi}_{2} \mathrm{Se}_{3}$, Nat. Phys. 8, 459, 2012

[11] P. Puneet, R. Podila, M. Karakaya, S. Zhu, J. He, T. M. Tritt, M. S. Dresselhaus, A. M. Rao, Preferential Scattering by Interfacial Charged Defects for Enhanced Thermoelectric Performance in Few-layered ntype $\mathrm{Bi}_{2} \mathrm{Te}_{3}$, Sci. Rep. 3, 3212, 2013

[12] K. Kadel, L. Kumari, WZ Li, J.Y. Huang, P.P. Provencio, Synthesis and Thermoelectric properties of $\mathrm{Bi}_{2} \mathrm{Se}_{3}$ Nanostructures, Nanoscale Res. Lett $6,57,2011$

[13] M. Guo, Z. Wang, Y. Xu, H. Huang, Y. Zang, C. Liu, W. Duan, Z. Gan, S.-C. Zhang, K. He, X. Ma, Q. Xue, Y. Wang, Tuning thermoelectricity in a Bi2Se3 topological insulator via varied film thickness, New J. Phys. 18, 015008, 2016

[14] J. Navratil, J. Horak, T. Plechacek, S. Kamba, P. Lostak, J. S. Dyck, W. Chen, C. Uher, Conduction band splitting and transport properties of $\mathrm{Bi}_{2} \mathrm{Se}_{3}$, J. Solid State Chem. 177, 1704, 2004

[15] P.H. Le, C.-N. Liao, C.W. Luo, J.-Y. Lin, J. Leu, Thermoelectric properties of bismuth-selenide films with controlled morphology and texture grown using pulsed laser deposition, Appl. Surf. Sci. 285P, 657 2013

[16] Z. Sun, S. Liufu, L. Chen, Synthesis and characterization of nanostructured bismuth selenide thin films, Dalton Trans. 39, 10883, 2010

[17] X. Li, J. Yin, J. Zhou, Q. Wang, W. Guo, Exceptional high Seebeck coefficient and gas-flow-induced voltage in multilayer graphene, Appl. Phys. Lett. 100, 183108, 2012 